\title{
The Use of Eucalyptus Activated Biocarbon for Water Treatment-Adsorption Processes
}

\author{
Roberta M. Nunes, Damaris Costa, Nilce Ortiz* \\ Center for Environmental Chemistry, Institute for Nuclear and Energy Research-IPEN, São Paulo, Brazil \\ Email: *nortizbr@gmail.com
}

How to cite this paper: Nunes, R.M., Costa, D. and Ortiz, N. (2017) The Use of Eucalyptus Activated Biocarbon for Water Treatment-Adsorption Processes. American Journal of Analytical Chemistry, 8, 515-522.

https://doi.org/10.4236/ajac.2017.88037

Received: June 29, 2017

Accepted: August 27, 2017

Published: August 30, 2017

Copyright $\odot 2017$ by authors and Scientific Research Publishing Inc. This work is licensed under the Creative Commons Attribution International License (CC BY 4.0).

http://creativecommons.org/licenses/by/4.0/

\begin{abstract}
A biocarbon after activation process showed the removal percentage of $92 \%$ of methylene blue in solution, the equilibrium parameter- $\mathrm{RL}$ value was in the interval from 0 to 1 , with $46 \%$ of surface coverage degree. The Freundlich constant (n) was higher than 1 as an indication of the physical adsorption process. The Radlich-Peterson calculations obtained the higher $R^{2}$ value which $g$ constant near 1, a high similarity with Langmuir model. Temkin constant B1 was a positive indication of endothermic process. All calculations provided favorable results for the use of activated biocarbon for dye removing and possible for other organic substances.
\end{abstract}

\section{Keywords}

Biocarbon, Radlich-Peterson, Eucalyptus, Temkin

\section{Introduction}

Used worldwide as soil amendment the biocarbon was first cited in the literature as "Terra Preta de Indios" (Amazon Dark Earth) because the Brazil is the largest producer with enormous different kinds and quantities of fine biocarbon. The agroindustry produces different biomass as sugar-cane bagasse, wood and paper mill waste, biofuel waste industry and sewage sludge are making Brazil an important actor in biocarbon production and use for different scenarios [1].

The biocarbon is amorphous materials characterized by its expanded surface area, porosity and the availability of surface active adsorption centers which the ability to bond and remove gases, metals, and organic compounds. Currently, there is an imbalance in the carbon cycle, with $\mathrm{CO}_{2}$ emissions grow to the atmosphere and little Carbon retention by the environment compartments, the direct effect is the necessity to develop methods to sequester the atmospheric 
carbon for a longer time. Agricultural, forestry, and industrial residues, poultry manure, urban waste, and sewage sludge are potential sources of biomass and biomaterials. Such properties can be used as renewable energy sources and can contribute to significant environmental benefits through the utilization of the by-product, biocarbon, charcoal or biochar.

Thus, the use of organic residues for biocarbon production represents a major contribution in control of contamination of soil and water resources, as well as a valid form of Carbon sequester and retention. Nevertheless, more studies are necessary regarding the activation processes and chemical characteristics that can affect the soil adsorption processes involved in geo-availability of chemical elements, which allows development of measures to decrease leaching and immobilization, in particular for organics and toxic metals pollution [2].

The biocarbon characteristics result in several mechanisms for toxic substances removal the precipitation and co-precipitation the presence of phosphate ions and carbonate plays a major role in precipitation formation. Also, the high $\mathrm{pH}$ level promotes the hydroxide precipitation and possible the cation exchange. It has high CEC, and it could adsorb cations ions in solution or biocarbon and water suspensions. The electrostatic interaction and amount of negative charges in the surface can absorb positive toxic metals by electrostatic adsorption, and the porous structures indicate the physical adsorption by large surface area, the complexation mechanism and the presence of functional groups as phenol-OH, $\mathrm{C}=\mathrm{C}$, and $\mathrm{C}=\mathrm{O}$ complexing and fixing the toxic metals [3].

The low-cost soil and water treatment are necessary using the biomass after pyrolysis and activation. The biomass is the photosynthetic product resulting from $\mathrm{CO}_{2}$, water, and sun energy. About $90 \%$ of the biomass consists of Carbon and Oxygen, with a typical average elementary composition of 50\% wt of Carbon and $40 \mathrm{wt} \%$ of Oxygen. Other elements are Hydrogen $5 \mathrm{wt} \%$ and Nitrogen $1 \mathrm{wt} \%$ and trace elements as sulfur and chlorine. The biomass has the cellulose as the primary content and the high pyrolysis temperatures and time conversion rates improve the biocarbon conversion and adsorption capacity but also increase the transportation, furnace maintenance, and total production cost.

The research goal is to reach the enhancement of biocarbon adsorption effectiveness by simple chemical activation process using the parameters optimization and doses adjustments. There are many published works of activated biocarbon responsible for fixing and reducing pesticides and toxic metals on polluted soil and water. Some studies point out the promising biocarbon applications lead to positive results, especially regarding physical, chemical, biological soil properties and also control the mobility of environmental pollutants, such as organics and toxic metals.

The development of a simple chemical, a low-cost biocarbon activation process is the primary goal searched by researcher, environmental scientists and also agriculture business dealers mainly from continental agricultural countries like Brazil. 


\section{Materials and Methods}

The micronized eucalyptus Urophyla biocarbon was a solid waste with low cost and small particle size used in these experiments; the chemical activation improved the surface area and adsorption efficiency. A series of activation processes were performed to absorb and remove methylene blue (MB) from synthetic solutions. The MB adsorption provides valuable measurements about the activation process efficiency.

In literature, there are some biocarbon activation methods, Table 1 . The high toxic zinc ions and the high cost of the phosphates made those activation processes difficult to be used in the experiments. The calculations of the adsorbed mass of $\mathrm{MB}$ is proportional to the total biocarbon surface area, as follow e.g. $0.254 \mathrm{mg}$ of absorbed $\mathrm{MB}$ was an indication of $208 \times 10^{-2} \mathrm{~nm}^{2}$ covered by MB molecule, as surface area [4] [5] [6].

Langmuir isotherm calculations can be used to quantify and characterize the adsorption processes, Equation (1) and Equation (2). The calculation of surface coverage degree $(\theta)$ of the activated biocarbon indicated the activation process efficiency [7].

$$
\begin{gathered}
C_{e} / q_{e}=1 / K_{L}+\left(b_{L} / K_{L}\right) C_{e} \\
\theta=b C_{e} /\left(1+b C_{e}\right)
\end{gathered}
$$

where: $q_{e}$ is the solid phase equilibrium concentration $\left(\mathrm{mg} \cdot \mathrm{g}^{-1}\right), C_{e}$ the liquid phase equilibrium concentration $\left(\mathrm{mg} \cdot \mathrm{mL}^{-1}\right)$ and $K_{L}\left(\mathrm{mg} \cdot \mathrm{g}^{-1}\right)$ and $b_{L}\left(\mathrm{~L} \cdot \mathrm{mg}^{-1}\right)$ are the Langmuir constants, and $\theta$ is the surface coverage degree.

$\mathrm{MB}$ is a potent cationic dye with a maximum spectrophotometric absorption of light around $650 \mathrm{~nm}$, and its molecule occupies an area of about $208 \times 10^{-2}$ $\mathrm{nm}^{2}$ [7]. The MB adsorbed mass is an important indication of the surface coverage degree $(\theta)$ of the activated biocarbon. Figure 1 shows the particle size on water suspension under ultrasonic dispersion Table 2. The distribution of the particle sizes by a laser analyzer shows wide particle distribution from $1.26 \mu \mathrm{m}$ up to $13.56 \mathrm{~mm}$, but $50 \%$ of the particles are small of $6.36 \mu \mathrm{m}$.

In literature, there are various chemical, thermal or photo-oxidation processes to quantify the remaining $C$ in the biocarbon residue. In spite of many researches considered the ultimate value the black $C$ and pyrogenic $C$ quantification methods, for the application point of view the $\mathrm{BC}$ quantification

Table 1. The comparison of total surface area obtained for biocarbon different activation processes.

\begin{tabular}{ccc}
\hline Activation agent & Surface area $\left(\mathrm{m}^{2} \cdot \mathrm{g}^{-1}\right)$ & References \\
\hline $\mathrm{K}_{2} \mathrm{CO}_{3}$ & 1.065 & Mestre [5] \\
Steam & 1.185 & Altenor [6] \\
$\mathrm{H}_{3} \mathrm{PO}_{4}$ & 1.272 & Altenor [6] \\
$\mathrm{ZnCl}_{2}$ & 1.249 & Khalili [7] \\
\hline
\end{tabular}




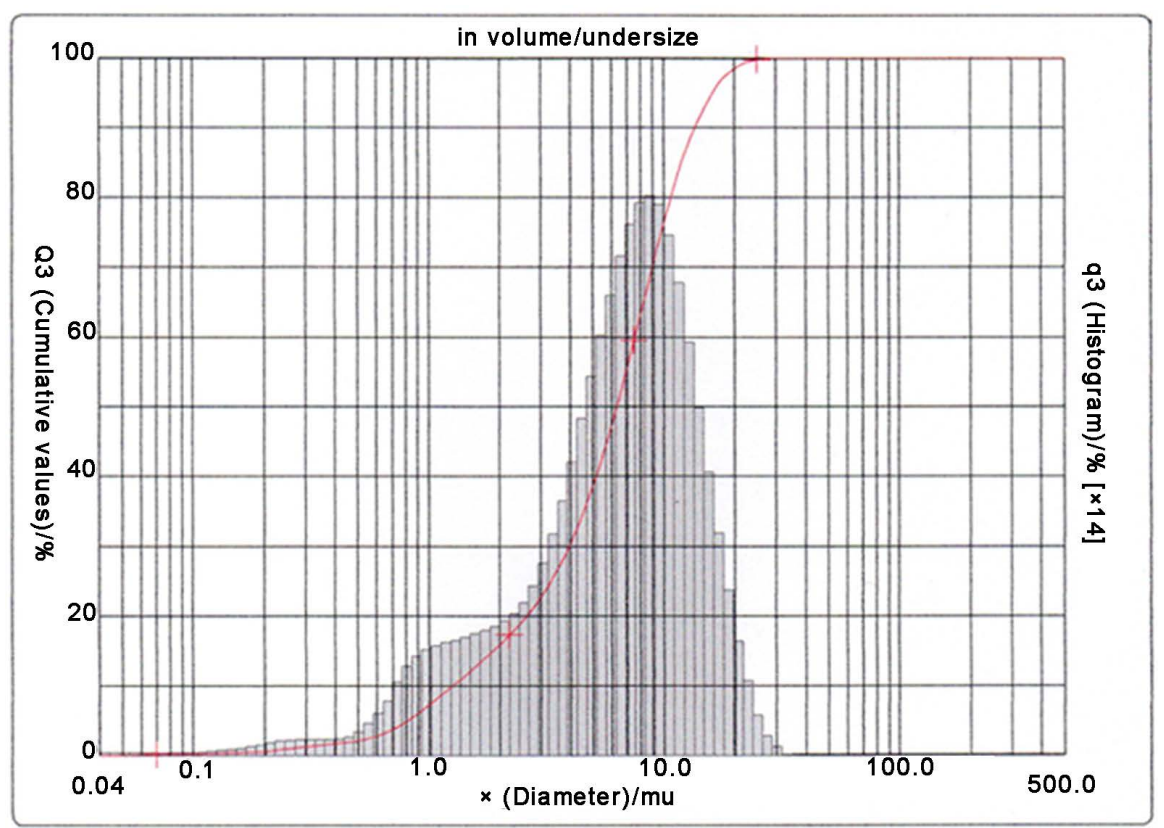

Figure 1. Particle size distribution of eucalipthus biocarbon (Cilas Equipment-1064).

Table 2. The removal percentage, Langmuir constants and surface coverage degree obtained for different activation agents.

\begin{tabular}{cccccc}
\hline $\begin{array}{c}\text { Activation } \\
\text { agents }\end{array}$ & Removal (\%) & $K_{L}\left(\mathrm{mg} \cdot \mathrm{g}^{-1}\right)$ & $b_{L}\left(\mathrm{~L} \cdot \mathrm{mg}^{-1}\right)$ & $\Theta$ & $\begin{array}{c}\text { Surface Area } \\
\left(\mathrm{m}^{2} \cdot \mathrm{MB} \cdot \mathrm{g}^{-1}\right)\end{array}$ \\
\hline $\mathrm{KCL}$ & 92 & 0.940 & 0.81 & 0.60 & 230.0 \\
$\mathrm{KHCO}_{3}$ & 88 & 0.119 & 0.564 & 0.57 & 145.0 \\
Water Steam & 79 & 0.775 & 1.02 & 0.29 & 121.9 \\
\hline
\end{tabular}

can be used for comparison but is not and end it self, but rather a means to an end [2] [6].

The eucalypt biocarbon was analyzed using MEV scanning microscopy. Figure 2 shows the crystalline structure with the high potentiality for surface area enhancement after activation.

Table 2 shows the activation agents used in the experiments. The orbital shaker mixed the biocarbon water suspension with $30 \mathrm{~g}$ of biocarbon (diameter $<0.074 \mathrm{~mm}$ ) and $15 \mathrm{~g}$ of $\mathrm{KCl}$ (PA-analytical grade) or $15 \mathrm{~g}$ of $\mathrm{KHCO}_{3}(\mathrm{PA})$ on $400 \mathrm{~mL}$ of distilled water for 6 hours. After the mixing period, the filtration step used a glass filtration apparatus with diameter membrane of $0.45 \mu \mathrm{m}$ separated the suspended solid from the aqueous medium, the laboratory oven at $90^{\circ} \mathrm{C}$ for 24 hours dried the solid obtained after filtration. The steam activated biocarbon used a $50 \mathrm{~mL}$ of water in a steam pistol applied in an A4 paper filter covered by $30 \mathrm{~g}$ of biocarbon, after the application, the biocarbon was dried open in the environment, and the procedure was repeated twice when finally the steam activated biocarbon was collected and dried at $90^{\circ} \mathrm{C}$ for $24 \mathrm{~h}$.

The adsorption processes used different $\mathrm{MB}$ initial concentrations in the range of 0.5 to $2.0 \mathrm{mg} \cdot \mathrm{L}^{-1}$ with $1.0 \mathrm{~g}$ of activated biocarbon in a controlled environment 


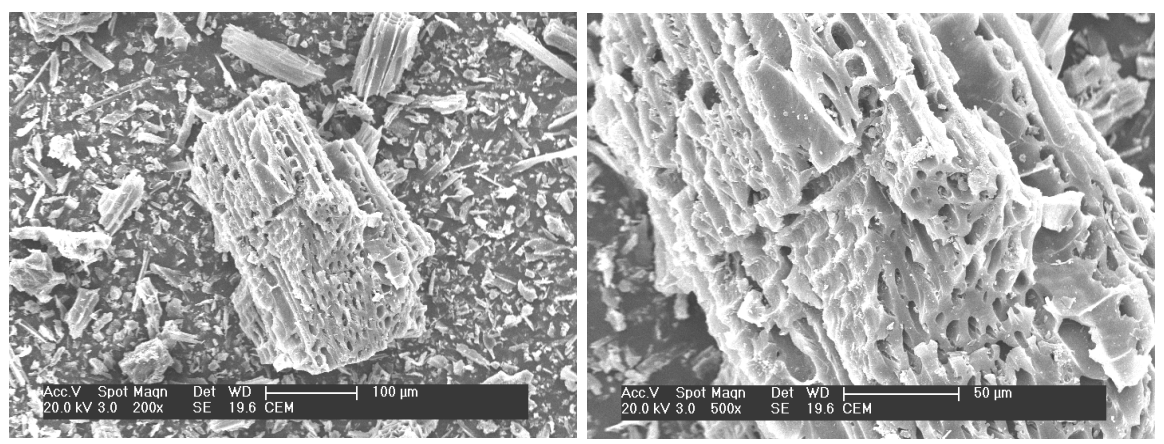

Figure 2. SEM micrography of biocarbon sample with $200 \times$ and $500 \times$ of magnification.

Table 3. Table Langmuir, Freundlich, Radlich-Peterson and Temkin constants.

\begin{tabular}{ccc}
\hline & \multicolumn{2}{c}{ Isotherm constants } \\
\cline { 2 - 3 } Langmuir & $R L=0.087$ & Coverage degree $\Theta=0.60$ \\
\hline Freundlich & $n=1.2$ & $K_{f}=1.01$ \\
Radlich-Peterson & $g=1.08$ & $K_{r}=1.01$ \\
Temkin & $B=0.851\left(\mathrm{~J} \cdot \mathrm{mol}^{-1}\right)$ & $K_{t}=131.63$ \\
\hline
\end{tabular}

of $\mathrm{pH} 5.5$ and temperature of $30^{\circ} \mathrm{C}$ kept constant. Each 30 minutes of stirring had the collection of $\mathrm{MB}$ and biochar suspension promoting the measurement of adsorption processes efficiency and improvement. The centrifugation of the aliquots was for $15 \mathrm{~min}$ at $1500 \mathrm{rpm}$, and the $\mathrm{MB}$ solution content was measured using the spectrophotometer UV-Vis VARIAN E1 at $\lambda=663 \mathrm{~nm}$, and the calibration curves were prepared previously. The systems reached the equilibrium after 120 min of continuous stirring. The equilibrium time of 120 minutes is a clear indication of favourable adsorption kinetics.

\section{Results and Discussion}

The biocarbon activated with potassium chloride showed the higher surface area and adsorption efficiency followed by the activated with potassium carbonate and finally water steam, Table 3 . The adsorption removal percentages were $90 \%$, $88 \%$ and $79 \%$ respectively. The results obtained using Equation (1) and Equation (2) indicated the surface coverage degree and confirm the most efficient activation with potassium chloride, followed by potassium carbonate and water steam coverage degree $(\theta)$ of $2.87 \%, 5.72 \%$ and $6.04 \%$. The correspondent surface areas were $230.0,145.0$ and $121.9\left(\mathrm{~m}^{2} / \mathrm{g}\right)$.

The potassium chloride and water steam showed promising results for biocarbon activation with high $\mathrm{MB}$ removal percentage. The lower KL values for $\mathrm{KHCO}_{3}$ activation indicate possibly the interference of large hydrate $\mathrm{HCO}_{3}^{-}$ anions interfering with the surface adsorption phenomena, reducing the viable adsorption bounding on porous and surface area [7] [8]. The promising results promoted the use of activated biocarbon as a commercial adsorbent for water 
treatment and confirm the needs of adsorption process studies with parameters optimization and isotherm calculations. The Isotherm calculations of Langmuir, Freundlich, Radlich-Peterson and Temkin used the Equations (3)-(5) respectively [9] [10].

$$
\begin{gathered}
C_{e} / q_{e}=1 / Q_{0} b+C_{e} / Q_{0} \\
\log q_{e}=\log K_{f}+1 / n \log C_{e} \\
\ln \left(C_{e} / q_{e}\right)=g \ln C_{e}-\ln K_{r} \\
q_{e}=B_{1} \ln k_{t}+B_{1} \ln C_{e}
\end{gathered}
$$

where: $C_{e}=$ equilibrium concentration $\left(\mathrm{mg} \cdot \mathrm{L}^{-1}\right) ; q_{e}=$ amount adsorbed at equilibrium $\left(\mathrm{mg} \cdot \mathrm{g}^{-1}\right) ; Q_{0}=$ adsorption capacity of the material [11], $b=$ energy of adsorption. The $K_{f}$ and $K_{r=}$ adsorption capacity $\left(\mathrm{L} \cdot \mathrm{g}^{-1}\right), n=$ efficiency of adsorption. The constant $g$ is an exponent between 0 and 1 [12] [13]. The constant $K_{t}$ is the equilibrium binding force $\left(1 \cdot \mathrm{mg}^{-1}\right)$ and $B_{1}\left(\mathrm{~J} \cdot \mathrm{mol}^{-1}\right)$ is related to adsorption heat. The biocarbon activated potassium chloride showed $92 \%$ of removal percentage with better correlation with Radlich-Peterson isotherm model (Figure 3) [14] [15].

In literature, there are many studies of biochar adsorption process [16]. The adsorbents as pine wood, pig manure, activated carbon and pulp and paper derived were used and the removal quantities were 3.99, 16.30, 1.66 and 48.30 $\mathrm{mg} \cdot \mathrm{g}^{-1}$ respectively [17] [18]. The findings of the batch sorption of MB suggest the high adsorption capability of the activated biocarbon with $K_{L}$ of $0.94 \mathrm{mg} \cdot \mathrm{g}^{-1}$ or removal percentage of $92 \%$; The $R L$ value was in the interval from 0 to 1 with $46 \%$ of coverage degree. The obtained $K_{L}$ value was similar with those found in literature and was promising considering the use of a natural biomass residue of renewable source and will improve with the optimization of the processes parameters.

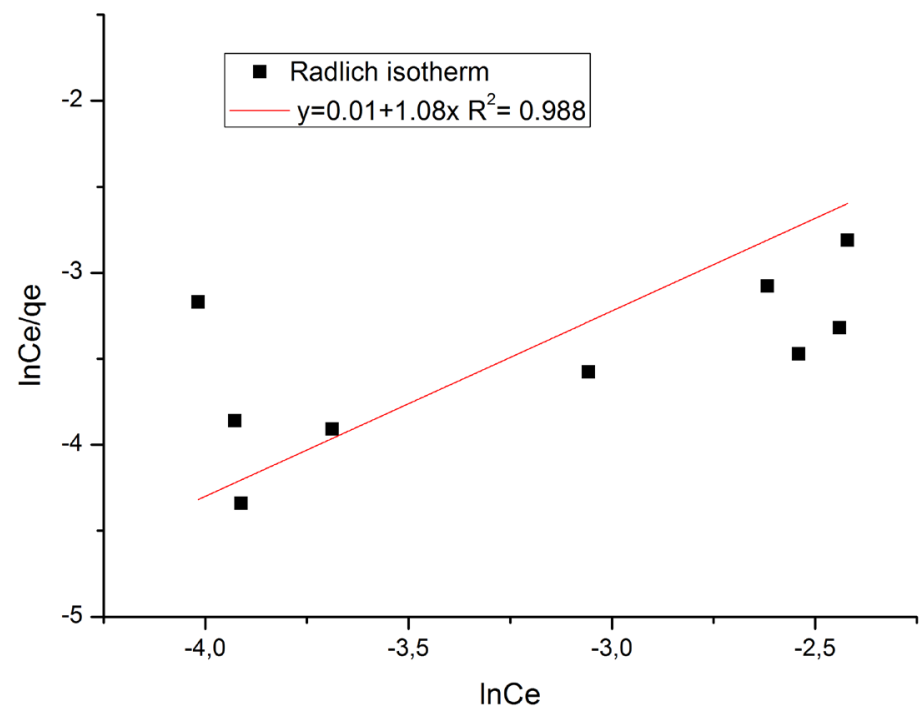

Figure 3. Radlich-Peterson isotherm line equation. 
The Freundlich $\mathrm{n}$ constants higher than 1 were a clear indication of the physisorption as the primary mechanism. The Radlich-Peterson model was the higher $R^{2}$ which constant $g$ near 1 , representing a high similarity with the Langmuir model. The Temkin constant B1 is calculated using the slope of the linear equation with a positive indication of an endothermic process. All calculations provide favorable results for the use of activated biocarbon as a low cost promising adsorbent for dye removing and possible another organic substance.

\section{Conclusion}

The investigation showed that activated biocarbon derived from eucalyptus biomass was an effective adsorbent for the MB removal from aqueous solutions. The biocarbon with the highest surface area and removal percentage was activated with $\mathrm{KCl}$ and fits best to Radlich-Peterson isotherm and the correlation coefficient value $R^{2}$ was 0.988 . For Temkin model, the constant B1 was 0.851 $\left(\mathrm{J} \cdot \mathrm{mol}^{-1}\right)$ as direct relation with an endothermic process. Thus the biocarbon derived from eucalyptus biomass activated with $\mathrm{KCl}$ can be used as an efficient and profitable adsorbent with surface area enhancement.

\section{Acknowledgements}

The authors would like to acknowledge The National Council for Scientific and Technological Development (CNPq) and São Paulo Research Foundation (Fapesp).

\section{References}

[1] Novotny, E.H., Maia, C.M.B.F., Carvalho, M.T.M. and Madari, B.E. (2015) Biochar: Pyrogenic Carbon for Agricultural Use-A Critical Review. Revista Brasileira de Ciência do Solo, 39, 321-344. https://doi.org/10.1590/01000683rbcs20140818

[2] Liu, R., Wang, Y (2017) Comparison of Characteristics of Twenty-One Types of Biochar and Their Ability to Remove Multi-Heavy Metals and Methylene Blue in Solution. Fuel Processing Technology, 160, 55-63.

https://doi.org/10.1016/j.fuproc.2017.02.019

[3] Hameed, B.H., Tan, I.A.W. and Ahmad, A.L. (2009) Preparation of Oil Palm Empty Fruit Bunch Based Activated Carbon for Removal of 2,4,6-Trichlorophenol: Optimization Using Response Surface Methodology. Journal of Hazardous Materials 164, 1316-1324. https://doi.org/10.1016/j.jhazmat.2008.09.042

[4] Gleysteen, I.F. and Scheffler, G.H. (1960) Structure of Activated Carbons and Adsorption from Solution. Proceedings of the Fourth Conference on Carbon, University of Buffalo, New York, 15-19 Jun 1960. Pergamon Press, ISBN 978-1-4831-9835-4.

[5] Mestre, A. S. et al. (2011) Activated Carbons from Sisal Waste by Chemical Activation with $\mathrm{K}_{2} \mathrm{CO}_{3}$ : Kinetics of Paracetamol and Ibuprofen Removal from Aqueous Solution. Bioresource Technology, 102, 8253-8260. https://doi.org/10.1016/j.biortech.2011.06.024

[6] Altenor, S. et al. (2009) Adsorption Studies of Methylene Blue and Phenol onto Retriever Roots Activated Carbon Prepared by Chemical Activation. Journal of Hazardous Material, 165, 1029-1039. https://doi.org/10.1016/j.jhazmat.2008.10.133

[7] Khalili, N.R., et al. (2000) Production of Micro- and Mesoporous Activated Carbon 
from Paper Mill Sludge. Effect of Zinc Chloride Activation, Carbon, 38, 1905-1915. https://doi.org/10.1016/S0008-6223(00)00043-9

[8] Ortiz, N., Pires, M.A.F. and Bressiani, J.C. (2001) Use of Steel Converter Slag as Nickel Adsorber to Wastewater Treatment. Waste Management, 21, 631-635. https://doi.org/10.1016/S0956-053X(00)00123-9

[9] Sampranpiboon, P. and Chamkeitkong, P. (2010) Equilibrium Isotherm, Thermodynamic and Kinetic Studies of Lead Adsorption onto Pineapple and Paper Waste Sludges. International Journal of Energy and Environment, 4, 88-98. ISSN 2251-6832 (Online).

[10] Mirzaeil, N., Hossini, H. and Mahvi, A.H. (2016) Equilibrium and Kinetics Studies of Direct Blue 71 Adsorption from Aqueous Solutions Using Modified Zeolite. Adsorption Science and Technology, 7, 1-15 https://doi.org/10.1177/0263617416684836

[11] Al Zubaidi, I.A.H., Al Tamimi, A.K.A. and Ahmed, H. (2016) Remediation of Water from Crude Oil Spill Using a Fibrous Sorbent. Environmental Technology \& Innovation, 6, 105-114. https://doi.org/10.1016/j.eti.2016.08.002

[12] Tharaneedhar, V., Senthil, P., Kumar, A., Saravanan, C. and Ravikumar, V. (2017) Prediction and Interpretation of Adsorption Parameters for the Sequestration of Methylene Blue Dye from Aqueous Solution Using Microwave Assisted Corn Activated Carbon. Sustainable Materials and Technologies, 11, 1-11. https://doi.org/10.1016/j.susmat.2016.11.001

[13] Ahmad, R. and Hasseb, S. (2017) Adsorption of PbII on Menthe Piperita Carbon (MTC) in Single and Quaternary Systems. Arabian Journal of Chemistry, 10, 412-421. https://doi.org/10.1016/j.arabjc.2012.09.013

[14] Vuono, D., Catizzone, E., Aloise, A., Polichio A., Agostino, R.G., Migliori, M. and Giordano, G. (2017) Modelling of Adsorption of Textiles Dyes over Multi-Walled Carbon Nanotubes: Equilibrium and Kinetics. Chinese Journal of Chemical Engineering, 25, 523 -532. https://doi.org/10.1016/j.cjche.2016.10.021

[15] Fan, S., Wang, W.Z., Tang, J. and Li, X. (2017) Removal of Methylene Blue from Aqueous Solution by Sewage Sludge Derived Biochar: Adsorption Kinetics, Equilibrium, Thermodynamics, and Mechanism. Journal of Environmental Chemical Engineering, 5, 601-611. https://doi.org/10.1016/j.jece.2016.12.019

[16] Hu, X., Ding, Z., Zimmerman, A.R., Wang, S. and Gao, B. (2015) Batch and Column Sorption of Arsenic onto Iron-Impregnated Biochar Synthesized through Hydrolysis. Water Research, 68, 206-216. https://doi.org/10.1016/j.watres.2014.10.009

[17] Lonappan, L., et al. (2016) Adsorption of Methylene Blue on Biochar Microparticles Derived from Different Waste Materials. Waste Management, 49, 537-544. https://doi.org/10.1016/j.wasman.2016.01.015

[18] Mori, A. and Maksimov, I.L. (1999) On the Temkin Model of Solid-Liquid Interface. Journal of Crystal Growth, 20, 297-304. https://doi.org/10.1016/S0022-0248(98)01397-9 
Submit or recommend next manuscript to SCIRP and we will provide best service for you:

Accepting pre-submission inquiries through Email, Facebook, LinkedIn, Twitter, etc. A wide selection of journals (inclusive of 9 subjects, more than 200 journals)

Providing 24-hour high-quality service

User-friendly online submission system

Fair and swift peer-review system

Efficient typesetting and proofreading procedure

Display of the result of downloads and visits, as well as the number of cited articles Maximum dissemination of your research work

Submit your manuscript at: http://papersubmission.scirp.org/

Or contact ajac@scirp.org 